\title{
Reclaiming Teaching for Teacher Education: Towards a Spiral Curriculum
}

\author{
Gert Biesta ${ }^{1}$ \\ Maynooth University, Ireland \\ University of Humanistic Studies, The Netherlands \\ gert.biesta@mu.ie;www.gertbiesta.com
}

\begin{abstract}
Many policy makers and educational researchers seem to be convinced that teaching matters. Unfortunately, such a case for teaching and teachers tends to rely on a rather one-dimensional view of what counts in education - namely the production of measurable learning outcomes - and a rather mechanistic view of what counts as education - namely teaching as an intervention that is aimed at producing particular effects. Such views about teaching and education more generally are also affecting programmes of teacher education. In this paper I raise some questions about such views about the significance of teaching, on the assumption that the future of teacher education needs to be informed by a different understanding of what teaching is and what it is for. I make a case for a multi-dimensional view of the purposes of education and for teaching as an act of communication and interpretation that always requires judgement about that 'what' and the 'what for.' Placing such judgement at the centre of teacher education suggests that the structure of the curriculum for teacher education should be spiral rather than linear-cumulative.
\end{abstract}

\section{Keywords}

teaching - teachers - teacher education - purposes of education - communication judgement - Aristotle - spiral curriculum - Jerome Bruner

1 Recent and forthcoming books by this author include: The Beautiful Risk of Education (Routledge: 2014); The Rediscovery of Teaching (Routledge 2017); Obstinate Education: Reconnecting School and Society (Brill|Sense 2019); Educational Research: An Unorthodox Introduction (Bloomsbury 2019). 


\section{Introduction: The Future of Teacher Education and the Future of Teaching}

In this paper I wish to argue that any discussion about the future of teacher education needs to start with an exploration of the future of teaching. After all, it is only when we have an idea of what teaching is and what it ought to be, and when we have an accurate understanding of the pressures contemporary teaching is under, that we can begin to ask questions about the 'how,' the 'what' and the 'what for' of teacher education. While this may sound obvious, many discussions about teacher education tend to skip this step and go straight into discussions about the practicalities of educating teachers, often relying on particular notions of teaching that, in themselves, remain unquestioned. One common and rather influential trope in contemporary discussions about education that easily leads to such a distortion, is the suggestion that teaching matters and that, by implication, teachers matter (see, for example, OECD 2005; McKinsey \& Co. 2007; Donaldson 2010; Department for Education 2010).

While this claim may sound attractive, the idea that teaching matters is often made with reference to research that apparently shows that teachers are the most influential determinant of pupil achievement (see, e.g., Hattie 2003). Yet it is precisely in such claims that problems begin to surface. One problem is the reduction of teachers and their work to that of a 'determinant,' as it conflates statistical correlation with the complex relational work of teachers (on the latter see Frelin 2013). A second problem is that pupil achievement is often operationalised in very narrow and one-dimensional ways, rather than covering the full spectrum of what might - and in my view should - matter in education (on this see Biesta 2010). And thirdly, there is the problematic assumption that teaching is some kind of 'intervention' that is supposed to produce 'effects,' rather than that teaching is seen as an act of communication that carries meaning for all those involved and thus relies on the open work of interpretation rather than on a simplistic logic of cause and effect.

Viewed in this way, the suggestion that teaching matters is not so much an endorsement of the complex work of teachers but may actually be contributing to the undermining of teachers' professional agency (see Biesta 2017; Priestley, Biesta \& Robinson 2015). It may contribute, in other words, to a significant redefinition of what teaching is and what it is for, and of what this implies for the work of the teacher.

Given this, how might we reclaim teaching, for the sake of teaching itself and for the sake of teacher education? In this paper I will seek to respond to this question in the following way. I will start with a brief historical reconstruction of recent developments that have led to the current predicament about 
teaching and teacher education. I will then argue for the need for a double 'push-back' concerning, firstly, conceptions of educational quality and, secondly, conceptions of teaching. I will address the question of educational quality through some reflections on the question of educational purpose, arguing against a mono-dimensional understanding of the question of purpose. I will address the question of conceptions of teaching by locating teaching firmly in what Aristotle has referred to as the domain of the variable, the domain of actions and possible consequences, highlighting the need for teachers to make judgements about the 'how' of teaching but also about the 'what for,' and for the need to see both judgements as intimately connected. I will conclude with the suggestion that if teaching can be recovered along these lines, teacher education may best be served by what, following Bruner (1960), we might term a spiral curriculum rather than a linear-cumulative one.

\section{The Slippery Slope: Where Did it All Start, Where Did it Go Wrong, and Where Have We Ended Up?}

It is important to acknowledge that the current predicament regarding teaching and the state of education more generally, is not the result of some evil plot but more so the outcome of a range of interlocked events that, step by step, moved from laudable intentions to problematic consequences. ${ }^{2}$ At the very start of the chain we can find a clear social justice argument that is difficult to contest, namely the suggestion that every child and young person, irrespective of who they are, where they are or where they are from, should have access to good education. This starting point then raised the question how we can ensure that education is everywhere of sufficient quality which, in turn, raised the question how we can actually judge the quality of education.

One decisive step was taken when the question of judgement about the quality of education became translated into the question how we can measure the quality of education. A second decisive step was taken when the question of measuring the quality of education turned into the question how we can measure the quality of educational outcomes (see, for example, Spady 1994; and for an 'early' critique Jansen 1998). The question which outcomes should be measured, soon turned into the question which outcomes can be measured,

2 My brief reconstruction can partly be read as a historical account of what has happened in educational policy, research and practice over the past 25 years or so, and partly as a systematic account of the way in which supporters of educational measurement tend to make their case. 
and so the good intentions of the social justice argument eventually turned into the current 'age of measurement' (Biesta 2010), in which the key question is whether we are (still) measuring what is being valued, or whether we have reached a situation where many just value what is being measured, and take the latter as a valid indicator of the quality of education. And all this has been heavily 'supported' by the rise of GEMI, the 'global education measurement industry' (Biesta 2015a; see also Hopmann 2008).

The result of these developments is not confined to the current obsession with measurement and with the widespread comparison of educational systems in order to indicate which system is better and which system is best, but has actually affected almost all dimensions of education. In many countries, and also at a 'global' scale, it has contributed to a very narrow definition of what apparently 'counts' in education, namely achievement in a small number of curricular areas (often language, science and mathematics). At the same time, it has influenced perceptions about what counts as education, not just in shifting the focus from the quality of provision and processes to the quality of outcomes (on this shift see also Priestley \& Biesta 2013), but also in reconceptualising the dynamics of education in terms of interventions and effects, that is, in terms of an input-output logic that quickly turns education into a matter of production.

These developments have resulted in a degrading of teachers, transforming them from thinking, judging and acting professionals into 'factors' in the production of learning outcomes. They have contributed to the rise of a culture of performativity in education, where indicators of quality become redefined as definitions of quality, so that, for example, the position on a league table is no longer just interesting information but becomes a strategic target for educational institutions or national education systems. And what is perhaps most worrying, is how all this has contributed to an inner erosion of education itself, making the actors in education increasingly cynical about what really matters as long as performance indicators are met - a development documented in chilling detail by Dianne Ravitch (see Ravitch 2011).

If we cannot recover teaching from these developments, then there is probably little hope for the future of teacher education, because even laudable and enlightened approaches to teacher education would be quickly undermined by the erosion of teaching that is taken place in educational practice. That this erosion is going on, is visible in discussions about education quality, which tend to focus on a narrow set of outcomes. It is also visible in the way teachers are beginning to see themselves and the work they do, opting for such phrases as 'facilitators of learning' or 'creators of learning environments', where the ultimate aim seems to have become that of generating 'learning outcomes.' It is 
visible in the ways in which educational accountability has lost its democratic dimension and increasingly has become bureaucratic (Gewirtz 2002 remains an important early account of these developments). And it is visible in the ways in which the logic of evidence is entering classrooms, where teachers are not just being forced to only do those things for which there is evidence that they work (for a penetrating critique see Davis 2017), but where the logic of experimental research and, more specifically, of randomised controlled trials, is beginning to displace the logic of teaching (on this issue see also Biesta, in press).

What kinds of 'push back' might be needed, then, to regain, recover and reclaim teaching from these developments? I wish to suggest that work is needed at two 'fronts' at least. One concerns definitions of what counts in education; the other concerns conceptions of what counts as education.

\section{3}

\section{Pushing Back: What Counts in Education?}

I have already alluded to the fact that one of the problems with contemporary education is its focus on a small number of 'learning outcomes.' As long as we accept that these are the ones that really count - and quite often this would mean conceding to the fact that these are the only ones that really count - it will be difficult to argue against the idea that all efforts of and in the education system should be geared towards these outcomes. This means that the first 'push back' that is needed, concerns the very definition of what counts in education.

One line I have been pursuing in my own work (starting with Biesta 2004) is the suggestion that the problem is not just with the question which learning outcomes should matter, but that the very rise of the language of learning in education and the subsequent 'learnification' (Biesta 2010) of educational discourse and practice have hampered attempts at articulating what should count in education. The main problem with the rise of the language of learning - which is visible in such developments as referring to pupils and students as 'learners,' to the teacher as a 'facilitator of learning,' to schools as 'places for learning' or 'learning environments,' or to adult education as 'lifelong learning' is that the language of learning is, in itself, not an educational language and thus runs the risk of masking the questions that should be asked in education.

A quick way to indicate the problem, is by saying that the point of education is never that children and young people just learn - and it is useful to pause here and consider the many instances from education policy, research and everyday practice where not much more than this is being said - but rather that 
children and young people learn something, learn it for a reason, and learn it from someone. Here lies the fundamental difference between the language of learning, which is a process language that in some way is 'empty' with regard to content and purpose, and the language of education, which always raises questions of content, purpose and relationships.

Of the three - content, purpose and relationships - the question of purpose is central and fundamental, because if we do not know what we seek to achieve with our educational endeavours, we have no criterion for judging what kind of content should be brought into play, nor how relationships should be utilised and what kind of educational 'forms' are the most appropriate ones. To say that the question of purpose is central and fundamental is not to make any claims about who should articulate the purpose of the educational endeavour; there are a range of options (teachers, parents, students, policy makers), although teachers do need to play an important role in this. It is also not to suggest that the purpose of the educational endeavour should be formulated as a clear aim or target that should just be met or achieved - the current obsession with visibility (as in 'visible learning') has, for example, marginalised the idea that education can and perhaps also should be an adventure of which the outcome is fundamentally unknown.

In my view the most urgent intervention needed in current discussions about educational quality is to highlight the fact that education is never orientated towards only one purpose, but that in all instances of education - from teaching the 'basics' of language and mathematics up to the most complex forms of vocational and professional education - there are always three dimensions or domains 'in play' (for an uptake of this idea in the context of Dutch education policy see Onderwijsraad 2016).

The idea here (developed in more detail in Biesta, 2010) follows from the simple observation that education is always about the presentation and acquisition of 'something' (knowledge, skills, dispositions) and in this regard education is always orientated towards the qualification of children and young people, that is, enhancing their ability to act. Some would argue that this is all that education should be concerned with, i.e., that the only task of the school is to convey knowledge and skills and that anything beyond this should be left to the family or the public sphere. Yet even if schools were just to stick to knowledge and skills, they would - as the research on the hidden curriculum has been showing for decades - be sending out strong messages about desirable ways of life and of living together, about what matters and doesn't matter, and so on. This reveals that it is inevitable that all education, when enacted, is also engaged in socialisation, in communicating and providing children and young people with access to and orientation in traditions, cultures, ways of 
being, doing and acting. On the one hand this is what happens as soon as education takes place; on the other hand, it can be argued that this is part of what schools should be doing in addition to the work of qualification.

Next to qualification and socialisation I wish to suggest that education always also has an 'impact' on the formation of the person - positively or negatively - and that there is therefore also a task in engaging with the question what desirable (and undesirable) ways of engaging with this dimension are. I have referred to this dimension as that of subjectification, highlighting that what is at stake here is the question how children and young people can be supported and encouraged to exists as free and responsible subjects of their own actions, rather than as objects of the actions and desires of others.

There are, of course, many further questions to ponder - not least about the actual knowledge, skills and dispositions that should be presented in the curriculum; about the traditions, cultures and practices that should be (re)presented in the school; and about how we can encourage children and young people to take up the challenge of existing-as-subject in meaningful ways. But highlighting that the point and purpose of education can never be onedimensional and can never be reduced to just a small set of learning outcomes in the domain of qualification, is at least a first step in reclaiming meaningful notions of teaching and the work of the teacher.

\section{4}

\section{Pushing Back: What Counts as Education?}

The focus on a small number of allegedly measurable learning outcomes, is not just problematic because of its narrow view of what matters in education. It has also brought with it an understanding - and perhaps we could even say: a redefinition - of teaching as an intervention that is supposed to produce certain effects. It has, in other words, reconfigured teaching in terms of an inputoutput logic, where the ambition is not just to make sure that teachers perform the 'right' inputs to generate such outputs, but where also a huge research effort has emerged, known as evidence-based education, that seeks to provide teachers which knowledge about what (allegedly) 'works' towards the production of such outcomes (see Smeyers \& DePaepe 2006; Biesta 2007).

While some have suggested that if we transform evidence-based education into evidence-informed education we reopen the space for teacher judgement, I wish to argue that the problem is not about whether teaching should be 'based upon' evidence or be 'informed by' it, but about the assumptions about educational knowledge and action that are contained in the very idea of 'evidence.' The point I wish to make here is an old one - William James, for 
example, already clearly articulated it in 1899 in his Talks to Teachers by stating that "(p)sychology is a science, and teaching is an art; and sciences never generate arts directly out of themselves" (James 1899, p. 14) - but there is an ongoing need to make this point in response to the mistaken idea that with more knowledge and research we should eventually be able to find the 'magic bullet' of teaching.

The philosopher who, in my view, remains very helpful in this discussion is Aristotle, first and foremost because he was one of the first Western philosophers who took the bios praktikos, the practical life, as his main area of concern, and not the bios theoretikos, the life of theory. ${ }^{3}$ The first thing to acknowledge, is that for Aristotle the theoretical life is not the life of abstraction and speculation but concerns the encounter with what he refers to as "the necessary and the eternal" (Aristotle 1980, p. 140). It is, for example, about the stars in the sky or the movement of planets, but also about the necessary aspects of living nature where, for example, an acorn cannot become anything but an oak tree. Aristotle refers to the knowledge in this domain as episteme. This is often translated as 'science,' although we have to be aware that this is not identical to the modern conception of science and is more accurately understood as 'knowledge-about-what-is-necessary-and-eternal.' The main point Aristotle is making about episteme, is that once we have correct knowledge about processes or events that are necessary and eternal, this knowledge will not change for the simple fact that that which the knowledge is about will itself not change.

While Aristotle acknowledges that there is a place for such a view of knowledge, his main contribution to the discussion lies in the simple acknowledgement that most of what takes place in and matters to our lives as human beings has nothing to do with the necessary and eternal but actually takes place in the domain of the 'variable' (Aristotle 1980, p. 142). This is the domain of our actions and the possible consequences of such actions. We can of course be obsessed with a 'quest for certainty,' as John Dewey called it (see Dewey 1929), and there may be aspects of our practical lives where we can reach a degree of stability, predictability and certainty, but in so many aspects of our lives the best we can hope for is to gain knowledge about possibilities: about what might happen as a result of our actions, but not about what always necessarily will happen (on this point see also Davis 2017).

3 My enthusiasm for Aristotle must be qualified in light of the existence of recent scholarship on Aristotle in education that seems to pursue a rather conservative agenda for 'character education.' I wish to signal that the orientation of this work is very different from the views about education I have explored in my own writings in 'conversation' with Aristotle. 
There is a strong tendency to think of such knowledge as 'merely' practical, and of having a lower status than so-called 'scientific' knowledge. But here it is again John Dewey who has highlighted that modern science, because of its use of the method of experimentation, is actually itself engaged in creating knowledge about actions and possible consequences, rather than knowledge about the necessary and eternal. Its mode of knowledge generation is, to put it differently, profoundly practical. Such knowledge can be very useful, but we shouldn't think of it as fundamentally different from the knowledge we gain in our own everyday endeavours (see Dewey 1929; see also Biesta \& Burbules 2003). We should, in other words, not make modern experimental science any bigger or more important than it is, although we should also not make it any smaller. The real challenge is to have an appropriate understanding of what contemporary experimental science is and can achieve, which includes the need for an astute understanding of its limitations (see Dewey 1929; and also Latour 1979).

Aristotle's discussion about our actions in the domain of the variable introduces a further distinction that is relevant for the discussion, namely that between the art of 'making' - which we can describe as craft - and the art of 'doing' - which we can describe as art in the narrower sense of the word. The art of making - poiesis in Greek - refers to the production of things. Or in the slightly more precise formulation Aristotle gives: it is about "how something may come into being which is capable of either being or not being" (which means that it is about the variable, not about what is eternal and necessary), and about things "whose origin is in the maker and not in the thing made" (which distinguishes 'poiesis' from biological phenomena such as growth and development) (see Aristotle 1980, p. 141). The kind of knowledge at stake here is called techne, which Aristotle defines as "knowledge of how to make things" (Aristotle 1980, p. 141).

Craft is an appropriate word here, not just because craft has to do with making things, with bringing things about, but also because craft is never the mechanistic execution of recipes or protocols or scripts, but crucially involves judgement. Teaching has many of the qualities Aristotle lists as belonging to 'poiesis.' It is, for example, never about just following recipes, protocols or scripts, but requires judgement about what this concrete and in some respects unique situation requires. Teachers bring knowledge and skill to the situation, but also need to have a keen eye for their students, for where they are and where they might be going, and for the circumstances under which they teach. And even with all preparation and good intentions, it remains an open question whether teachers will manage to achieve what they set out to achieve. In this sense teaching is always a 'risky business' (see Biesta 2014). 
The reason why teaching carries this risk, is because teaching, unlike the way the planets move in the solar system, is not a process of mechanical push and pull but of human interaction and communication. Teaching is, however, not about letting things grow or emerge, because, unlike acorns, the future for human beings is radically open and one could argue that the ultimate 'point' of education is to encourage children and young people to engage with the openness of their own future and do so wisely. Yet this is not the whole story, because there is one way in which teaching is precisely not a matter of poiesis. This is because in a very fundamental sense teaching is precisely not about the production of things. Students, after all, are not the things we produce, nor should the overall ambition of education be to produce learning outcomes and do so effectively. Students are human beings who we encounter in educational relationships, and this encounter is a matter of communication not of production.

What is valuable about Aristotle's categories, is that he acknowledges that our life in the domain of the variable is not just about our engagement with the material world but includes our social and political existence. Here, so Aristotle argues, we need a different art, not the art of making, but the art of doing, which Aristotle calls praxis. Praxis, to put it briefly, is about the promotion - not the production - of eudamonia, of living one's life well, individually and with others. Praxis is "about what sort of things conduce to the good life in general" (Aristotle 1980, p. 142). We could say, therefore, that praxis is about good action, but good action should not be understood as a means for bringing about something else. Good action, as Aristotle puts it, "itself is its end" (Aristotle 1980, p. 143).

The kind of judgment that is needed here is not about how to act but about "what is to be done" (Aristotle 1980, p. 143; emphasis added). Aristotle refers to this kind of judgment as phronesis, which is usually translated as practical wisdom. It is a "reasoned and true state of capacity to act with regard to human goods" (Aristotle 1980, p. 143). So, while craft - poiesis - is an important dimension of teaching that has to do with teachers' know-how, teaching is never just a matter of how to do things, but always needs to keep an orientation on what teaching is for, which is where the question of what education is for, the question of purpose, enters the discussion again. This, by the way, also has important implications for the craft-dimension of teaching, because with regard to the 'how' of teaching, the question is never just about the most effective ways of reaching certain aims or achieving certain ends. In teaching we must always ask whether the most effective ways are morally acceptable and educationally meaningful.

Aristotle's categories are helpful, not just because he provides a sound argument for locating teaching in the domain of the variable - of possibilities, not 
certainty - but also because, within this domain, he makes the helpful and important distinction between poeiesis and praxis. This, on the one hand, helps to see what goes wrong when teaching becomes defined in terms of the logic of production and, on the other, shows that the judgement that is needed in teaching is always a 'double' judgement: about the how and the what for, and the two are fundamentally interconnected.

\section{5} Conclusion: Towards a Spiral Curriculum for Teacher Education

The suggestion I have explored in this paper is that the future of teacher education needs to consider the future of teaching and perhaps needs to consider this future first, particularly, so I have suggested, because in the contemporary 'age of measurement' teaching itself seems to be 'under siege,' to use a popular phrase from the educational literature (Giroux \& Aronowitz 1987; Mortimore 2013). I have focused on two developments which, in my view, are significantly contributing to the contemporary erosion of teaching. One is the shift towards (the language of) learning which has side-lined questions of what learning in education should be about and, most crucially, what is should be for. In order to push back against this development, I have suggested the need for putting the question of educational purpose back at the centre of the discussion, and for acknowledging the problem with mono-dimensional answers to the question what education should be for.

The other development concerns the redefinition of teaching in terms of an input-output logic of interventions and effects, which is not just influencing the practice of teaching but also seems to be key in contemporary efforts to make teaching evidence-based or evidence-informed. The push back I have suggested here is to firmly locate teaching in the domain of the variable - the domain of actions and possible consequences - in order to acknowledge that teaching is an art, not a science. In addition, going back to Aristotle, I have suggested that teaching is a 'double art,' consisting of both poeisis and praxis, making-action and doing-action, and that the two are necessarily intertwined. All this brings to the fore that teaching is impossible without judgement judgement about how to do things and judgement about what is to be done and it is here that the question of the 'nature' of teaching connects back to the question of educational purpose.

One could argue - and I have done so in more detail elsewhere (Biesta $2015 \mathrm{~b}$ ) - that a recovery of teaching along these lines, foregrounds the centrality of one question that is absolutely central for the art of teaching, which is the question "What, in this concrete situation, is educationally desirable?" or, in a slightly different phrasing that highlights that teaching is practical: "What, 
in this concrete situation, is the most desirable way 'forward'?" These questions suggest that teaching is never about recipes or protocols, as mentioned, but needs 'tailoring' to concrete and in a sense always unique situations, and such tailoring requires judgement. And such judgement is both about the 'how' and about the 'what for' and should always take the two question together.

One way to bring these issues into teacher education is in a linear or 'staged' version, where one would start with the 'how', that is, the way in which teacher students acquire knowledge and skills and would slowly, perhaps towards the end of their education, begin to raise questions about the 'what for.' This is a common way to think and 'do' curriculum, starting from the assumption that one should begin with things that are easy and within the grasp of where students are, and add complication gradually and at a later stage. More specifically, it is a way of thinking and 'doing' curriculum that starts with the practical and factual and brings normative judgement in at a later stage.

There is of course something to say in favour of such an approach, but one downside of such a 'staged' curriculum is that one creates artificial distinctions and then needs to make an effort, 'later on,' to integrate the different parts. Also, and this is perhaps the more serious problem, by separating out, for example, the 'how' from the 'what for', the knowledge and skills from the normative judgements, one also creates the impression that such a separation is actually possible, whereas one could argue that practical and normative questions always appear together in teaching and cannot be separated out.

A rather different way to organise the education of teachers, therefore, would be to start with the whole - that is to introduce the question as to what, in this situation, is an educationally desirable way forward - from day one, and keep expanding, transforming, deepening and just 'kicking around' this question throughout the whole course of study. In my view, this is not only a more honest way to let teacher students encounter the 'essence' of the practice of education. It may also make it possible to constantly keep questions about the how and the what for 'in conversation,' thus deepening both students' understanding of the way in which how-questions impact on what-for-questions, and the way in which what-for-questions impact on how-questions.

The approach I am outlining here is close to what Jerome Bruner has termed a 'spiral curriculum' (see Bruner 1960) which is based on the simple but crucial assumption that "any subject can be taught effectively in some intellectually honest form to any child at any stage of development" (Bruner 196o, p. 33). The way in which I have suggested that we should try to reclaim and recover 
teaching in an age of measurement may, in my view, best be served by a curriculum of teacher education that takes this simple assumption as its key organising principle.

\section{References}

Aristotle (1980). The Nicomachean Ethics. Oxford: Oxford University Press.

Biesta, G.JJ. (2004). Against learning. Reclaiming a language for education in an age of learning. Nordisk Pedagogik 23, 70-82.

Biesta, G.J.J (2007). Why 'what works' won't work. Evidence-based practice and the democratic deficit of educational research. Educational Theory $57(1), 1-22$.

Biesta, G.J.J. (2010). Good education in an age of measurement: Ethics, politics, democracy. Boulder, Co: Paradigm Publishers.

Biesta, G.J.J. (2015a). Resisting the Seduction of the Global Education Measurement Industry: Notes on the Social Psychology of PISA. Ethics and education 10(3), 348-360.

Biesta, G.JJ. (2015b). How does a competent teacher become a good teacher? On judgement, wisdom and virtuosity in teaching and teacher education. In R. Heilbronn \& L. Foreman-Peck (Eds), Philosophical perspectives on teacher education (pp. 3-22). Oxford: Wiley Blackwell.

Biesta, G.J.J. (2017). Education, measurement and the professions: Reclaiming a space for democratic professionality in education. Educational Philosophy and Theory 49(4), 315-330.

Biesta, G.J.J. (in press). Educational research: An unorthodox introduction. London: Bloomsbury.

Biesta, G.J.J. (2014). The beautiful risk of education. Boulder, Co: Paradigm Publishers.

Biesta, G.J.J. \& Burbules, N. (2003). Pragmatism and educational research. Lanham, MD: Rowman and Littlefield.

Bruner, J. (1960). The process of education. Cambridge, MA: Harvard University Press.

Davis, A., (2017). It worked there. Will it work here? Researching teaching methods. Ethics and Education 23(3), 289-303.

Department for Education (2010). The importance of teaching. The schools white paper 2010. London: Her Majesty's Stationery Office.

Dewey, J. (1929). The quest for certainty: A study of the relation of knowledge and action. New York: Putnam.

Donaldson, G. (2010). Teaching Scotland's future: Report of a review of teacher education in Scotland. Edinburgh: Scottish Government.

Frelin, A. (2013). Exploring relational professionalism in schools. Rotterdam: Sense. 
Gewirtz, S., (2002). The managerial school: Post-welfarism and social justice in education. London/New York: Routledge.

Giroux, H.A. \& Aronowitz, S. (1987).Education under siege: The conservative, liberal and radical debate over schooling. New York: Routledge.

Hattie, J. (2003). Teachers make a difference - what is the research evidence? Professional Learning and Leadership Development, NSW DET.

Hopmann, S.T. (2008). No child, no school, no state left behind: Schooling in the age of accountability. Journal of Curriculum Studies 40(4), 417-456.

James, W. (1899). Talks to teachers on psychology: and to students on some of life's ideals. New York: Henry Holt.

Jansen, J.D. (1998). Curriculum reform in South Africa: A critical analysis of outcomesbased education. Cambridge Journal of Education 28(3), 321-331.

Latour, B. (1979). Science in action. Buckingham: Open University Press.

McKinsey \& Co. (2007). McKinsey Report: How the world's best performing school systems come out on top. (downloaded from: http://mckinseyonsociety.com/downloads/reports/Education/Worlds_School_Systems_Final.pdf).

Mortimore, P. (2013). Education under siege: Why there is a better alternative. Bristol: Policy Press.

OECD (2005). Teachers matter: Attracting, developing and retaining effective teachers. Paris: OECD.

Onderwijsraad (2016). De volle breedte van onderwijskwaliteit. Den Haag: Onderwijsraad.

Priestley, M. \& Biesta, G.J.J. (Eds.), (2013). Reinventing the curriculum. New trends in curriculum policy and practice. London: Bloomsbury.

Priestley, M., Biesta, G.J.J. \& Robinson, S. (2015). Teacher agency: An ecological approach. London: Bloomsbury.

Ravitch, D., (2011). The death and life of the great American school system: How testing and choice are undermining education. New York: Basic Books.

Smeyers, P. \& Depaepe, M. (Eds.), (2006). Educational research: Why 'what works' doesn't work. Dordrecht: Springer.

Spady, W. (1994). Outcome-based education: Critical issues and answers. Arlington, VA: American Association of School Administrators. 